\title{
Changes of Myogenic Reactive Oxygen Species and Interleukin-6 in Contracting Skeletal Muscle Cells
}

\author{
Hongying Pan, ${ }^{1}$ Xiaoyang Xu, ${ }^{1}$ Xuanming Hao, ${ }^{1}$ and Yajun Chen ${ }^{2}$ \\ ${ }^{1}$ College of Sports Science, South China Normal University, Guangzhou 510006, China \\ ${ }^{2}$ Department of Maternity and Child Health Care, School of Public Health, Sun Yat-Sen University, Guangzhou 510080, China
}

Correspondence should be addressed to Yajun Chen, chenyj68@mail.sysu.edu.cn

Received 13 January 2012; Revised 28 February 2012; Accepted 29 February 2012

Academic Editor: Michalis G. Nikolaidis

Copyright ( 2012 Hongying Pan et al. This is an open access article distributed under the Creative Commons Attribution License, which permits unrestricted use, distribution, and reproduction in any medium, provided the original work is properly cited.

\begin{abstract}
The aim of this study was to measure changes in myotube reactive oxygen species (ROS) and the production of interleukin (IL)-6 in electrically stimulated mouse C2C12 skeletal muscle cells. After five days of differentiation, myotubes were stimulated using an electrical stimulator set at $45 \mathrm{~V}$ at a frequency of $5 \mathrm{~Hz}$, with a pulse width of $20 \mathrm{~ms}$. Acute stimulations were performed for 45, 60, 75, 90 , or $120 \mathrm{~min}$ in each dish. ROSs were detected in the extracted cells directly using a fluorescent probe. IL-6 mRNA expression in C2C12 myotubes and IL- 6 concentration in C2C12 myotube supernatants were determined using real-time PCR and ELISA, respectively. Compared with control cells, ROS generation was significantly increased at $45 \mathrm{~min}$ after the onset of stimulation $(P<$ 0.01 ) and continued to increase, reaching a maximum at 120 min. IL-6 mRNA expression and IL-6 concentration in C2C12 cells were significantly increased after $75 \mathrm{~min}(P<0.01)$ and $120 \mathrm{~min}(P<0.05)$ of electrical stimulation (ES) compared with the control cells. Our data show that a specific ES intensity may modulate ROS accumulation and affect IL-6 gene expression in contracting skeletal muscle cells.
\end{abstract}

\section{Introduction}

Interleukin (IL)-6 is a cytokine with varied biological effects, is expressed by mesenchymal, epithelial, and other cell types, and is unregulated in response to noxious stimuli, other cytokines, and growth factors. Numerous studies have demonstrated that IL- 6 production is associated with muscle contraction and that the sympathoadrenal response to exercise plays only a minor role in the exercise-induced increase in plasma IL-6 [1]. Increases in the steady-state IL-6 mRNA level in skeletal muscle homogenates after long distance running suggest that skeletal muscle tissue might be a source of circulating IL-6 released during exercise [2]. Exercise does not induce an increase in plasma TNF- $\alpha$ level but induces a strong anti-inflammatory cytokine response with the appearance of IL- 6 in the circulation being particularly upregulated and preceding that of other cytokines [3]. The IL-6 gene is inactive in resting muscles but is rapidly activated by muscle contraction. Additionally, IL-6 acts as an energy sensor, which is dependent on the glycogen content in muscle [4]. Low glycogen levels have been shown to induce IL-6 gene transcription in skeletal muscle during exercise.
More recent studies have shown that IL- 6 release from muscle during exercise may be related to free radical metabolism, especially with reactive oxygen species (ROS) generation [5]. The generation of ROS is a normal occurrence during in vivo aerobic processes $[6,7]$. Exercise is an effective stimulation method and is accompanied by an increased generation of free radicals, resulting in a measurable degree of oxidative modifications to various molecules $[8,9]$. Although the increase in circulating levels of IL-6 after exercise is well documented, the cellular source and stimulus for its release remain elusive. A key limitation of these studies is that the experimental models were not physiological. Thus, in vivo studies are essential to define the role of IL-6 in skeletal muscle during exercise.

To examine whether skeletal muscle cells produce IL-6 and to identify possible stimuli for its release that are relevant to muscle contraction, we used differentiated $\mathrm{C} 2 \mathrm{C} 12$ skeletal muscle cells (myotubes) as a skeletal cell model of electrical stimulation to imitate skeletal muscle contraction, as previously reported [10-12]. Previous data has shown that this pattern of stimulation can bring about a variety of functional 
and structural changes in myotubes [13, 14]. It has been reported that control of myotube contraction using electrical pulse stimulation can induce large and rapid changes in the mRNA expression of genes encoding mitochondrial proteins. These mRNA increases result from a disruption in the equilibrium that exists between gene transcription and mRNA stability during nonadaptive steady-state conditions. Irrcher and Hood have shown that the contractile activity-mediated induction of transcription factor mRNA expression is highly divergent in $\mathrm{C} 2 \mathrm{C} 12$ myotubes. This variability in transcription factor mRNA induction and turnover is likely important for the time-dependent, gene-specific transcription events that are responsible for many muscle phenotypic adaptations to contractile activity at the level of contractile proteins and mitochondrial biogenesis [15].

Thus, the purpose of this study was to investigate the changes in ROS level and the production of IL-6 generated by skeletal myocyte contraction. We hypothesized that ROS generation induced by skeletal muscle contraction may be one of the factors regulating muscle-derived IL- 6 production and release.

\section{Materials and Methods}

2.1. Reagents and Cell Culture. C2C12 skeletal muscle cells were obtained from the Institute of Basic Medical Sciences, Chinese Academy of Medical Sciences. The cells were cultured in growth medium (Dulbecco's modified Eagle's medium (DMEM) containing 10\% fetal bovine serum (FBS), $100 \mathrm{IU} / \mathrm{mL}$ penicillin, and $100 \mu \mathrm{g} / \mathrm{mL}$ streptomycin) in a humidified incubator at $37^{\circ} \mathrm{C}$ with $5 \% \mathrm{CO}_{2}$. When myoblast cultures reached confluence, they were switched to DMEM containing $2 \%$ heat-inactivated horse serum supplemented with antibiotics (differentiation medium) for five days, and the $\mathrm{C} 2 \mathrm{C} 12$ skeletal muscle cells were differentiated into myotubes.

2.2. Electrical Stimulation Protocol. The design of the electrical stimulation apparatus was derived by modification of the existing method [16, 17]. After five days of differentiation, myotubes were stimulated using an electrical stimulator, (TY-C type), set at $45 \mathrm{~V}$ at a frequency of $5 \mathrm{~Hz}$. Stimulations were performed acutely for 45, 60, 75, 90, and $120 \mathrm{~min}$, separately. Cell extracts obtained from each dish were prepared immediately after stimulation.

2.3. ROS Measurements. A fluorescent probe, $2^{\prime}, 7^{\prime}$-dichlorofluorescin diacetate (DCFH-DA), was used for the assessment of intracellular ROS formation in cultured $\mathrm{C} 2 \mathrm{C} 12$ myotubes [7]. This assay is a reliable method for the measurement of intracellular ROS such as hydrogen peroxide $\left(\mathrm{H}_{2} \mathrm{O}_{2}\right)$, hydroxyl radical $(\mathrm{OH} \bullet)$, and hydro peroxides $(\mathrm{ROOH})[11,16]$. Myotubes were loaded with the probe and incubated for $20 \mathrm{~min}$. After loading, the cells were washed in preparation for electrical stimulation, collected immediately, and then placed in the spectrofluorometer to determine the ROS production at the excitation and emission wavelengths of $522 \mathrm{~nm}$ and $488 \mathrm{~nm}$, respectively. The peak value of luminescence as a function of time was taken after subtracting the value of the blank signal (luminescence of the illuminated medium).

2.4. The IL-6 mRNA Measurements. Total RNA was isolated with TriZol and reverse transcribed with Moloney murine leukemia virus (M-MLV) (Promega, USA). RT-PCR was performed using Taq DNA polymerase (Promega, USA). The sequences for the primers were as follows: for $\beta$-actin cDNA: $5^{\prime}$-CGT GAA AAG ATG ACC CAG ATC A-3' ${ }^{\prime}, 5^{\prime}$-CAC AGC CTG GAT GGC TAC GT-3'; IL-6 mRNA: $5^{\prime}$-TCC AGC CAG TTG CCT TCT TGG- $3^{\prime}, 5^{\prime}$-TCT GAC AGT GCA TCA TCG CTG- $3^{\prime}$. The conditions used were $94^{\circ} \mathrm{C}$ for $1 \mathrm{~min}, 94^{\circ} \mathrm{C}$ for 30 seconds, $50^{\circ} \mathrm{C}$ for 30 seconds, $72^{\circ} \mathrm{C}$ for $1 \mathrm{~min}$, repeated for a total of 39 cycles, final extension was performed at $72^{\circ} \mathrm{C}$ for $10 \mathrm{~min}$. The products were run on a $1.5 \%$ agarose gel and visualized under a UV lamp. The point where the two visualized bands ( $200 \mathrm{bp}$ from the amplification of the native IL- 6 cDNA and $400 \mathrm{bp}$ from the competitor molecule amplification) were of equal intensity was considered as the isopoint of the reaction (where equal starting concentrations of IL-6 cDNA and competitor existed in the PCR mix). The cycle number was chosen for each primer pair that maintained approximately exponential amplification with the enriched sample.

2.5. The IL-6 Concentrations Measurements. C2C12 cells were grown in monolayers and allowed to differentiate after reaching confluence. They were then treated with ES for 45, 60, 75, 90, and $120 \mathrm{~min}$, separately. After ES treatment, the supernatants were collected and centrifuged for $20 \mathrm{~min}$ at $1000 \mathrm{~g} / \mathrm{min}$ in a tabletop microcentrifuge to remove floating cells. Following centrifugation, pellets were discarded and supernatants used for ELISA in accordance with the manufacturer's instructions. C2C12 cell monolayers in the multiwell plates were lysed with $1 \mathrm{~N} \mathrm{NaOH}$. Protein amounts per well were determined by the Bradford method and were used to normalize against the values obtained for cytokine release.

2.6. Analysis. Electrophoretic bands were observed under UV transillumination and immediately photographed using an imaging system (SYNGENE, USA). Bandscan 5.0 (USA) band analysis software was used for analysis of electrophoretic bands to calculate the brightness of each PCR amplification product.

Data are expressed as mean \pm standard deviation (SD). The means were compared using a two-sided Student's $t$ test. Significant differences were determined using one-way ANOVA. Statistical analysis was conducted using SPSS13.0 (SPSS Inc.). Differences were considered significant at $P<$ 0.05 .

\section{Results}

3.1. Estimation of Cell Differentiation Fusion. The monolayer organization, as directly observed by inverted phase contrast microscopy, changes during the differentiation of myoblasts 


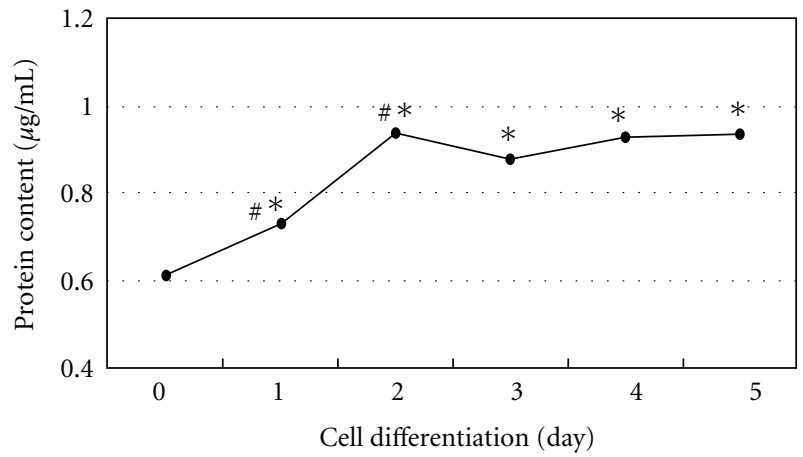

Figure 1: Total protein content of C2C12 myotubes during cell differentiation. When the $\mathrm{C} 2 \mathrm{C} 12$ skeletal muscle cells were differentiated into myotubes, the absorbance of each well (OD) was measured by standard curve with a microplate reader at $450 \mathrm{~nm}$ wavelength, and then the protein content was calculated through the standard curve. ${ }^{*} P<0.05$, significant difference compared with the first day, ${ }^{\#} P<0.05$, significant difference compared with the previous day.

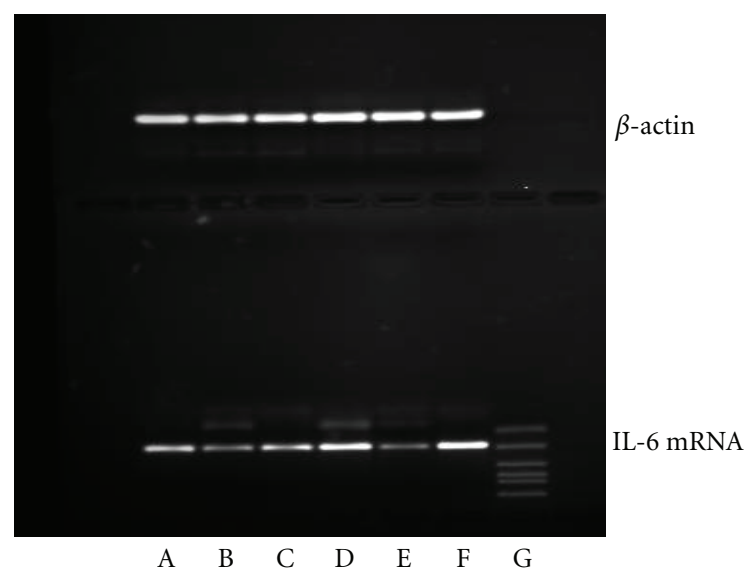

Figure 2: Gel photo of IL-6 mRNA expression from C2C12 myotubes following electrical stimulation. The products were run on a $1.5 \%$ agarose gel and visualized under a UV lamp. A: CN; B: ES 45 min; C: ES 60 min; D: ES 75 min; E: ES 90 min; F: ES 120 min; G: marker.

to myotubes. In the undifferentiated condition, myoblasts appear as fusiform or star-shaped cells, mostly flattened and closely adherent to the substrate. At the initial differentiation stage, intercellular spaces disappear, cells progressively align and occasionally elongate.

The bicinchoninic acid (BCA) assay was used to measure the synthesis and decomposition of $\mathrm{C} 2 \mathrm{C} 12$ myotube intracellular protein content. Figure 1 shows the changes in total protein content, which significantly increased from the undifferentiated state to the final phase. Total protein content increased, reaching maximal values at the 3rd day of differentiation, and then steadily increased and showed minimal values in the late differentiation stage.

3.2. ROS Generation after Acute Electrical Stimulation. To ensure accurate quantification of ROS generation, we applied the fluorescent probe DCFH-DA to mark cells after ES and
TABLE 1: ROS generation during different electrical stimulation times.

\begin{tabular}{lccc}
\hline & Mean \pm SD & & Mean \pm SD \\
\hline Control & $48.94 \pm 0.2547$ & ES75 & $592.30 \pm 3.398^{* \#}$ \\
ES45 & $341.54 \pm 3.4034^{* \#}$ & ES90 & $401.52 \pm 4.6214^{*}$ \\
ES60 & $503.52 \pm 3.3929^{* \#}$ & ES120 & $631.74 \pm 3.5515^{* \#}$ \\
\hline
\end{tabular}

The optical density (OD) values were measured using a fluorescent spectrofluorometer after ES. The peak value of luminescence as a function of time was taken after subtracting the value of the blank signal (luminescence of the illuminated medium).

${ }^{*} P<0.01$, significant difference compared with the control group,

${ }^{\#} P<0.05$, significant difference compared with the 90 min ES group.

TABLE 2: IL-6 mRNA expression during different electrical stimulation times.

\begin{tabular}{lccc}
\hline & Mean \pm SD & & Mean \pm SD \\
\hline Control & $0.5510 \pm 0.1637$ & ES75 & $0.7748 \pm 0.070^{\# *}$ \\
ES45 & $0.5679 \pm 0.05984$ & ES90 & $0.5701 \pm 0.0114$ \\
ES60 & $0.6417 \pm 0.1280$ & ES120 & $0.7367 \pm 0.1266^{*}$ \\
\hline
\end{tabular}

${ }^{*} P<0.05$, significant difference compared with the control group,

${ }^{\#} P<0.01$, significant difference compared with the control group.

subsequently measured the optical density (OD) values using a fluorescent spectrofluorometer. Table 1 shows that ROS generation significantly increased at $45 \mathrm{~min}$ after the onset of stimulation $(P<0.01)$ and continued to increase, reaching a maximum at $120 \mathrm{~min}$, compared with control cells.

\subsection{IL-6 mRNA Expression and IL-6 Concentration during} Different Electrical Stimulation Times. IL-6 mRNA expression in $\mathrm{C} 2 \mathrm{C} 12$ myotubes changed after ES (Table 2). Figure 2 shows the gel photo of IL- 6 mRNA expression from C2C12 myotubes after ES. The results show that IL- 6 mRNA concentration in $\mathrm{C} 2 \mathrm{C} 12$ myotube supernatants changed with differing times of ES.

IL-6 mRNA expression in C2C12 myotubes changed following electrical stimulation. IL-6 mRNA expression in C2C12 myotubes was significantly increased after $75 \mathrm{~min}(P<$ $0.01)$ and $120 \mathrm{~min}(P<0.05)$ of ES compared with the control group. Compared with the 90 min ES group, IL- 6 mRNA expression in the 75 and $120 \mathrm{~min}$ ES groups was significantly increased $(P<0.05)$.

IL-6 protein concentration from $\mathrm{C} 2 \mathrm{C} 12$ myotube supernatants was changed after ES. IL- 6 concentration increased in C2C12 myotube supernatants with increasing ES time compared with the control group, with the peak values appearing at 75 and $120 \mathrm{~min}(P<0.01)$. Compared with the $90 \mathrm{~min}$ ES group, IL- 6 concentration in the 75 and 120 min ES groups was significantly increased $(P<0.05)$ (Table 3$)$.

\section{Discussion}

Contractile activity is a potent stimulus for the induction of numerous cellular adaptations in skeletal muscle [18]. To assess alterations in response to contractile activity, we used an isolated cellular system in the absence of neural and 
TABLE 3: IL-6 concentration during different electrical stimulation times.

\begin{tabular}{lccc}
\hline & Mean \pm SD $(\mathrm{pg} / \mathrm{mL})$ & & Mean $\pm \mathrm{SD}(\mathrm{pg} / \mathrm{mL})$ \\
\hline Control & $81.83 \pm 13.16$ & ES75 & $2800 \pm 69.28^{* \#}$ \\
ES45 & $347.17 \pm 59.28^{*}$ & ES90 & $274.17 \pm 13.58^{*}$ \\
ES60 & $674.33 \pm 51.99^{* \#}$ & ES120 & $675.33 \pm 86.09^{* \#}$ \\
\hline
\end{tabular}

${ }^{*} P<0.01$, significant difference compared with the control group, ${ }^{\#} P<0.05$, significant difference compared with the $90 \mathrm{~min}$ ES group.

humoral factors. The results show that electrical stimulation $(45 \mathrm{~V}, 5 \mathrm{~Hz}, 20 \mathrm{~ms})$ modulates ROS accumulation and affects the gene expression level of IL-6. However, these changes did not cause any significant cell damage, implying that the intracellular redox balance was maintained. Skeletal muscle myotubes displayed a large and rapid increase in ROS production during ES. ROS release after different contraction times in vitro has not been previously described. However, abundant in vivo evidence has demonstrated that ROS production is a stimulus for skeletal muscle adaptation to exercise training $[8,19]$. Previous reports support the concept that exercise-induced ROS generation alters muscle gene expression and contributes to exercise-induced adaptations of skeletal muscle in vivo [20]. A common approach in many of these studies is to abolish the signaling effects of exerciseinduced ROS production in skeletal muscle by treating animals with antioxidants. For example, two independent studies have recently concluded that antioxidant supplementation can impede important training adaptations in human skeletal muscle [21, 22]. Our previous studies have also demonstrated that ES of $\mathrm{C} 2 \mathrm{C} 12$ myotubes can induce rapid increases in ROS, induce cellular dysfunction, and induce mitochondrial dysfunction $[11,21]$. This change is inconsistent with results previously reported in vivo $[8,20]$.

ROS production in muscle cells elicited by ES is related to the voltage, frequency, and duration applied. Different intensities of ES can induce different changes in ROS production [7]. Silveira et al. used different ES intensities on muscle cells and found that intense ES $(50 \mathrm{~V}$, pulse width $1 \mathrm{~ms}$, pulse interval $0.01 \mathrm{~s}$ ) of muscle cells increased intra- and extracellular DCF fluorescence, a measure of oxidation, by $171 \%$ and $105 \%$, respectively, compared with control nonstimulated cells. In contrast, moderate stimulation $(50 \mathrm{~V}$, pulse width $1 \mathrm{~ms}$, pulse interval $0.1 \mathrm{~s}$ ) did not significantly increase the extracellular DCF fluorescence [7]. Increasing the stimulation frequency increases skeletal muscle contraction strength, which leads to increases in skeletal muscle mitochondrial activity and superoxide generation. McArdle et al. used ES $(30 \mathrm{~V}, 1 \mathrm{~Hz}$, pulse width $2 \mathrm{~ms}$ ) on differentiated rat satellite cells to study the time course of ROS release. The authors found that a short $(15 \mathrm{~min})$ contraction in satellite cells caused a rapid 40x increase in ROS [23]. This increase in ROS can cause skeletal muscle protein thiol modification, a transient decrease in SOD and catalase activity, and an increase in heat shock protein concentration. However, these changes did not cause any notable cell damage [24].

In this study, we used ES $(45 \mathrm{~V}, 5 \mathrm{~Hz})$ to simulate $\mathrm{C} 2 \mathrm{C} 12$ myotubes. We found that ROS production significantly increased with ES compared with the control nonstimulated cells, and the change in ROS generation followed a triphasic curve pattern, with the peaks appearing in the 75 and 120 min ES groups. This is similar to our previous findings using the same mode of ES [11, 12]. Our previous results showed that exercise-induced ROS changes are related to mitochondrial oxygen consumption and the regulation of the antioxidant system. Many in vivo studies have also shown that oxidative stress in skeletal muscle is a hallmark of pathophysiological states [19]. ROS production was evident across the physiological range of membrane potentials and was relatively insensitive to membrane potential changes [25]. Abnormally high levels of ROS and the simultaneous decline of antioxidant defense mechanisms can lead to damage of cellular organelles and enzymes. We hypothesized that ROSs are removed mainly by cellular antioxidant systems, which include antioxidant vitamins, protein and nonprotein thiols, and antioxidant enzymes under physiological conditions. However, when ROS production is excessive, such as during prolonged aerobic exercise, cellular antioxidant systems may be overwhelmed, leading to extensive cell and tissue damage. The exercise-induced IL- 6 production and secretion within skeletal muscle fibers suggests that IL-6 may play a role in energy supply and storage in muscle during and after exercise. The role is likely short term, physiological, and locally active within minutes or a few hours [26]. In the present study, we observed the changes in IL-6 mRNA expression and IL- 6 protein content in C2C12 myotubes at different ES times $(0,45,60,75,90$, and $120 \mathrm{~min})$. This is different from previous studies, which suggest that the IL- 6 mRNA level in skeletal muscle is markedly increased during exercise [2729]. IL-6 protein has been shown to accumulate in contracting muscle fibers and be released in large amounts into plasma. Furthermore, transcriptional activation of the IL-6 gene in the skeletal muscle of humans is highly elevated during prolonged exercise $[5,30]$. Additional studies have shown that the time and intensity of exercise required to accumulate IL-6 protein within contracting muscle are not well defined. However, duration of exercise has been shown to be the single most important factor that determines the magnitude of the systemic IL-6 response [29]. Our results suggest that IL-6 mRNA expression in $\mathrm{C} 2 \mathrm{C} 12$ myotubes changed with differing ES times. IL-6 mRNA expression in both C2C12 myotubes and supernatants was significantly increased in the 75 and 120 min ES groups, compared with the control group.

Few studies have addressed the relationship between myogenic ROS and IL-6 after exercise in vivo. Some studies have shown that supplementation with vitamins $\mathrm{C}$ and $\mathrm{E}$ attenuated the systemic IL-6 response to exercise in plasma and skeletal muscle $[28,31]$. Antioxidants, such as vitamins $\mathrm{C}$ and $\mathrm{E}$, have been shown to attenuate oxidative stress at rest as well as in response to exercise, thereby reducing the generation of ROS [32]. Using C2C12 myotubes incubated with $\mathrm{H}_{2} \mathrm{O}_{2}$ at different concentrations, Kosmidou et al. found that IL- 6 content of cultured supernatants increased dependently after $24 \mathrm{~h}$. The authors concluded that ROSs stimulate IL-6 production from skeletal myotubes by increasing transcriptional activation of the IL- 6 gene through an NF- $\kappa$ Bdependent pathway [33]. In human bronchial epithelial cells, 
ROS-stimulated IL- 6 production is preceded by increases in IL-6 steady-state mRNA levels [34]. Keller et al. have suggested that induction of IL-6 expression in contracting myofibers may be largely responsible for the rise in circulating IL6 concentration during prolonged exercise [30]. Therefore, we speculate that similar mechanisms are likely active in contracting skeletal muscle and that ROS generation may play a role in the signaling processes by which $\mathrm{C} 2 \mathrm{C} 12$ myotubes adapt to changes in the pattern or duration of contractile activity.

It is well known that a variety of stresses can induce IL-6 upregulation. However, studies on the IL-6 response to electrical stimulation are scarce. To the best of our knowledge, this is the first report addressing the IL-6 response to ES. In the present study, we have shown that ES can cause changes in IL-6 mRNA expression, IL-6 protein content, and variable increases in ROS generation. We speculate that myogenic ROS generation is likely to mediate myogenic IL- 6 generation. However, in this study, we only investigated the possible link between myogenic IL- 6 and ROS after ES, not ROS produced by muscle vasoconstriction and subsequent IL- 6 release from skeletal myotubes. Thus, we cannot exclude the possibility that other intramuscular metabolic changes induce myogenic ROS production and subsequent release of IL-6 during exercise. Further studies are needed to investigate this possibility.

Our results indicate that electrical stimulation $(45 \mathrm{~V}$, $5 \mathrm{~Hz}, 20 \mathrm{~ms}$ ) may modulate ROS accumulation and affect the gene expression level of IL-6. Furthermore, the variation trend is consistent with the stimulation time. We speculate that ROS generated by skeletal muscle cell contraction may be one of the factors regulating muscle-derived IL- 6 production and release.

\section{Acknowledgments}

This work was supported by Research Start-up Grants from Sun Yat-Sen University "Hundred Talent Program". X. Xu supervised the research design and is the cofirst author of this study.

\section{References}

[1] R. L. Starkie, M. J. Arkinstall, I. Koukoulas, J. A. Hawley, and M. A. Febbraio, "Carbohydrate ingestion attenuates the increase in plasma interleukin-6, but not skeletal muscle interleukin-6 mRNA, during exercise in humans," Journal of Physiology, vol. 533, no. 2, pp. 585-591, 2001.

[2] K. Ostrowski, T. Rohde, M. Zacho, S. Asp, and B. K. Pedersen, "Evidence that IL-6 is produced in human skeletal muscle during prolonged running," Journal of Physiology, vol. 508, no. 3, pp. 949-953, 1998.

[3] M. A. Febbraio, A. Steensberg, R. L. Starkie, G. K. McConell, and B. A. Kingwell, "Skeletal muscle interleukin-6 and tumor necrosis factor- $\alpha$ release in healthy subjects and patients with type 2 diabetes at rest and during exercise," Metabolism, vol. 52, no. 7, pp. 939-944, 2003.

[4] S. Glund, A. Deshmukh, Y. C. Long et al., "Interleukin-6 directly increases glucose metabolism in resting human skeletal muscle," Diabetes, vol. 56, no. 6, pp. 1630-1637, 2007.
[5] C. E. Donges, R. Duffield, and E. J. Drinkwater, "Effects of resistance or aerobic exercise training on interleukin-6, C-reactive protein, and body composition," Medicine and Science in Sports and Exercise, vol. 42, no. 2, pp. 304-313, 2010.

[6] L. Q. Casey, A. G. Akos, R. T. Jason, and D. B. Martin, "The mechanism of superoxide production by the antimycin-inhibited mitochondrial Q-cycle," The Journal of Biological Chemistry, vol. 286, pp. 31361-31372, 2011.

[7] L. R. Silveira, L. Pereira-da-Silva, C. Juel, and Y. Hellsten, "Formation of hydrogen peroxide and nitric oxide in rat skeletal muscle cells during contractions," Free Radical Biology and Medicine, vol. 35, no. 5, pp. 455-464, 2003.

[8] A. M. Niess and P. Simon, "Response and adaptation of skeletal muscle to exercise-the role of reactive oxygen species.", Frontiers in Bioscience, vol. 12, pp. 4826-4838, 2007.

[9] H. M. Tse, M. J. Milton, S. Schreiner, J. L. Profozich, M. Trucco, and J. D. Piganelli, "Disruption of innate-mediated proinflammatory cytokine and reactive oxygen species third signal leads to antigen-specific hyporesponsiveness," Journal of Immunology, vol. 178, no. 2, pp. 908-917, 2007.

[10] T. Nedachi, H. Fujita, and M. Kanzaki, "Contractile C2C12 myotube model for studying exercise inducible responses in skeletal muscle," American Journal of Physiology, vol. 295, no. 5, pp. E1191-E1204, 2008.

[11] H. Y. Pan, X. Y. Xu, T. C. Liu, X. F. Zhou, Y. Zhang, and L. Wen, "Change in the generation of ROS in electrical-stimulated C2C12," Chinese Sports Medicine Journal, vol. 25, no. 1, pp. 46-49, 2006.

[12] X. Y. Xu, X. Zhao, T. C. Y. Liu, and H. Y. Pan, "Low-intensity laser irradiation improves the mitochondrial dysfunction of C2C12 induced by electrical stimulation," Photomedicine and Laser Surgery, vol. 26, no. 3, pp. 197-202, 2008.

[13] R. G. Dennis and D. E. Dow, "Excitability of skeletal muscle during development, denervation, and tissue culture," Tissue Engineering, vol. 13, no. 10, pp. 2395-2404, 2007.

[14] K. I. Yamasaki, H. Hayashi, K. Nishiyama et al., "Control of myotube contraction using electrical pulse stimulation for bio-actuator," Journal of Artificial Organs, vol. 12, no. 2, pp. 131-137, 2009.

[15] I. Irrcher and D. A. Hood, "Regulation of Egr-1, SRF, and Sp1 mRNA expression in contracting skeletal muscle cells," Journal of Applied Physiology, vol. 97, no. 6, pp. 2207-2213, 2004.

[16] J. M. Lin, "Determination of active oxygen species based on chemiluminescence methods," Acta Scientiae Circumstantiae, vol. 2, pp. 230-238, 2003.

[17] M. Marotta, R. Bragos, and A. M. Gomez-Foix, "Design and performance of an electrical stimulator for long-term contraction of cultured muscle cells," BioTechniques, vol. 36, no. 1, pp. 68-73, 2004.

[18] D. A. Hood, I. Irrcher, V. Ljubicic, and A. M. Joseph, "Coordination of metabolic plasticity in skeletal muscle," Journal of Experimental Biology, vol. 209, no. 12, pp. 2265-2275, 2006.

[19] S. K. Powers, J. Duarte, A. N. Kavazis, and E. E. Talbert, "Reactive oxygen species are signalling molecules for skeletal muscle adaptation," Experimental Physiology, vol. 95, no. 1, pp. 1-9, 2010.

[20] S. K. Powers and M. J. Jackson, "Exercise-induced oxidative stress: cellular mechanisms and impact on muscle force production," Physiological Reviews, vol. 88, no. 4, pp. 1243-1276, 2008 . 
[21] M. C. Gomez-Cabrera, E. Domenech, M. Romagnoli et al., "Oral administration of vitamin $\mathrm{C}$ decreases muscle mitochondrial biogenesis and hampers training-induced adaptations in endurance performance," American Journal of Clinical Nutrition, vol. 87, no. 1, pp. 142-149, 2008.

[22] M. Ristow, K. Zarse, A. Oberbach et al., "Antioxidants prevent health-promoting effects of physical exercise in humans," Proceedings of the National Academy of Sciences of the United States of America, vol. 106, no. 21, pp. 8665-8670, 2009.

[23] A. McArdle, D. Pattwell, A. Vasilaki, R. D. Griffiths, and M. J. Jackson, "Contractile activity-induced oxidative stress: cellular origin and adaptive responses," American Journal of Physiology, vol. 280, no. 3, pp. C621-C627, 2001.

[24] A. McArdle, J. van der Meulen, G. L. Close et al., "Role of mitochondrial superoxide dismutase in contraction-induced generation of reactive oxygen species in skeletal muscle extracellular space," American Journal of Physiology, vol. 286, no. 5, pp. C1152-C1158, 2004.

[25] E. L. Seifert, C. Estey, J. Y. Xuan, and M. E. Harper, "Electron transport chain-dependent and -independent mechanisms of mitochondrial $\mathrm{H}_{2} \mathrm{O}_{2}$ emission during long-chain fatty acid oxidation," The Journal of Biological Chemistry, vol. 285, no. 8, pp. 5748-5758, 2010.

[26] G. van Hall, A. Steensberg, M. Sacchetti et al., "Interleukin-6 stimulates lipolysis and fat oxidation in humans," Journal of Clinical Endocrinology and Metabolism, vol. 88, no. 7, pp. 3005-3010, 2003.

[27] S. Banzet, N. Koulmann, N. Simler et al., "Fibre-type specificity of interleukin-6 gene transcription during muscle contraction in rat: association with calcineurin activity," Journal of Physiology, vol. 566, no. 3, pp. 839-847, 2005.

[28] C. P. Fischer, N. J. Hiscock, M. Penkowa et al., "Supplementation with vitamins $\mathrm{C}$ and $\mathrm{E}$ inhibits the release of interleukin-6 from contracting human skeletal muscle," Journal of Physiology, vol. 558, no. 2, pp. 633-645, 2004.

[29] C. P. Fischer, P. Plomgaard, A. K. Hansen, H. Pilegaard, B. Saltin, and B. K. Pedersen, "Endurance training reduces the contraction-induced interleukin-6 mRNA expression in human skeletal muscle," American Journal of Physiology, vol. 287, pp. 1189-1194, 2004.

[30] C. Keller, A. Steensberg, H. Pilegaard et al., "Transcriptional activation of the IL- 6 gene in human contracting skeletal muscle: influence of muscle glycogen content," The FASEB Journal, vol. 15, no. 14, pp. 2748-2750, 2001.

[31] B. Nakhostin-Roohi, P. Babael, F. Rahmani-Nia, and S. Bohlooli, "Effect of vitamin C supplementation on lipid peroxidation, muscle damage and inflammation after 30-min exercise at 75\% VO2max," Journal of Sports Medicine and Physical Fitness, vol. 48, no. 2, pp. 217-224, 2008.

[32] A. A. Gaeini, N. Rahnama, and M. R. Hamedinia, "Effects of vitamin E supplementation on oxidative stress at rest and after exercise to exhaustion in athletic students," Journal of Sports Medicine and Physical Fitness, vol. 46, no. 3, pp. 458-461, 2006.

[33] I. Kosmidou, T. Vassilakopoulos, A. Xagorari, S. Zakynthinos, A. Papapetropoulos, and C. Roussos, "Production of interleukin-6 by skeletal myotubes: role of reactive oxygen species," American Journal of Respiratory Cell and Molecular Biology, vol. 26, no. 5, pp. 587-593, 2002.

[34] Y. Yoshida, M. Maruyama, T. Fujita et al., "Reactive oxygen intermediates stimulate interleukin-6 production in human bronchial epithelial cells," American Journal of Physiology, vol. 276, no. 6, pp. L900-L908, 1999. 


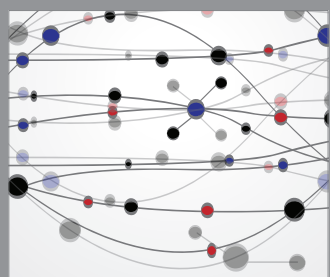

The Scientific World Journal
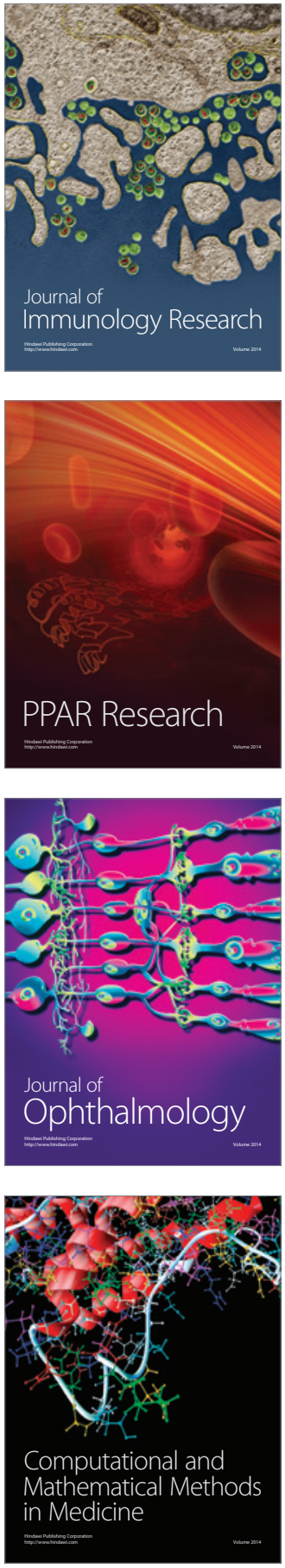

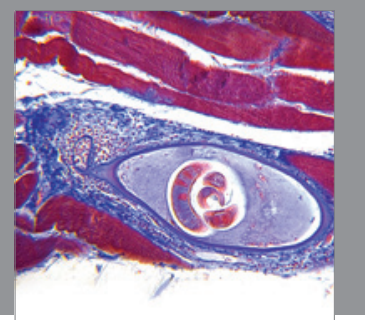

Gastroenterology

Research and Practice
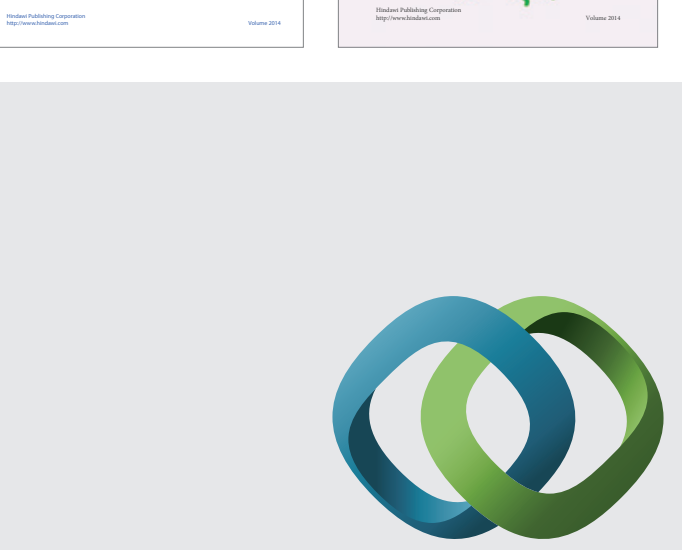

\section{Hindawi}

Submit your manuscripts at

http://www.hindawi.com
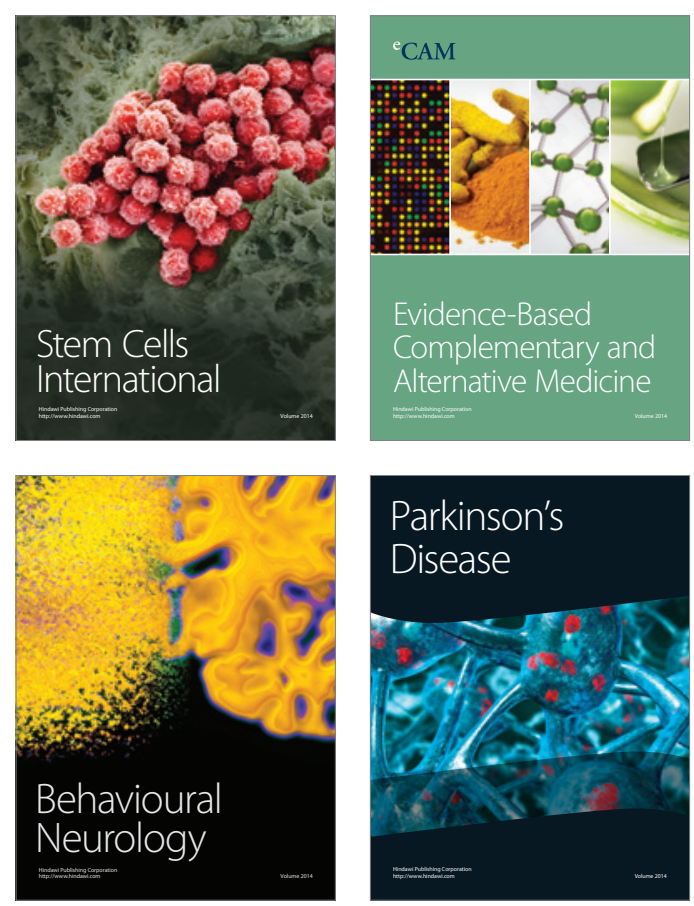

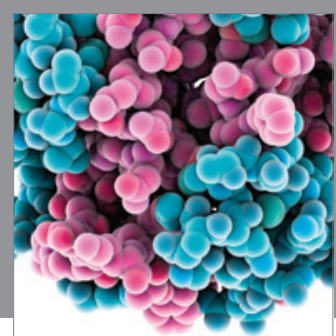

Journal of
Diabetes Research

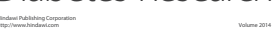

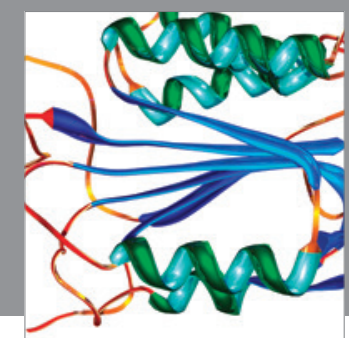

Disease Markers
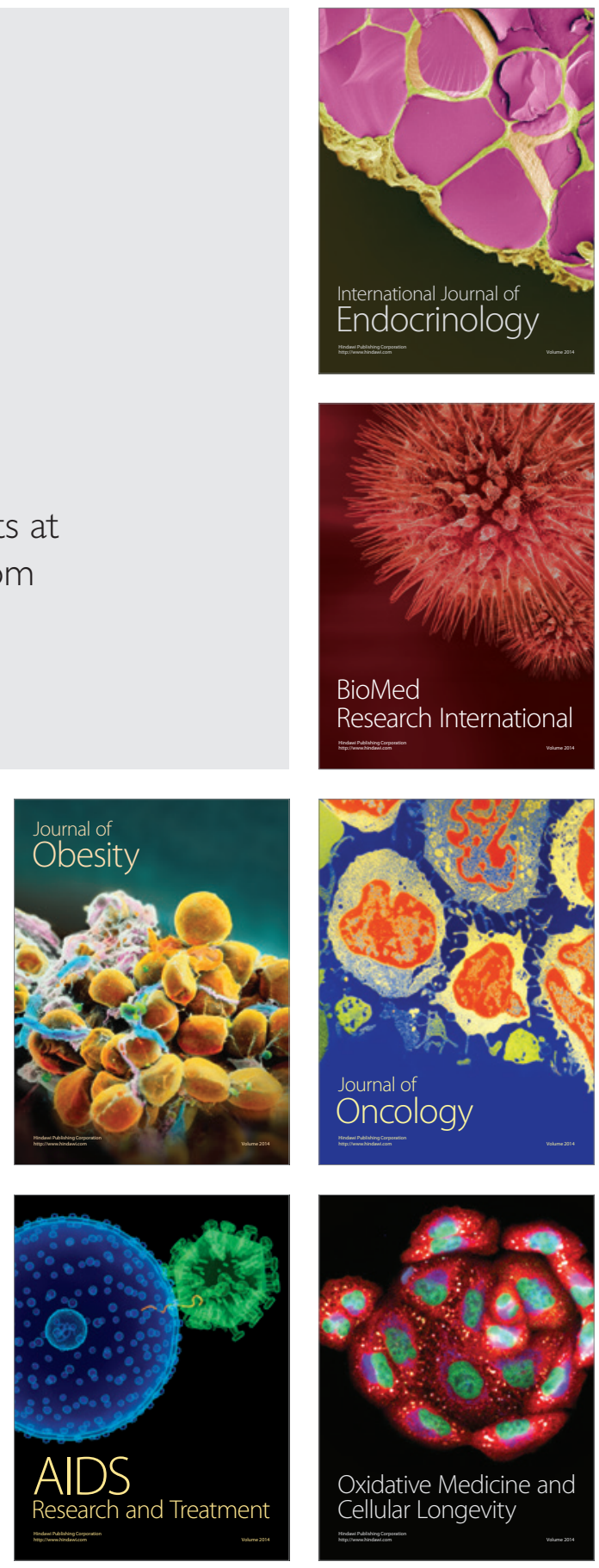